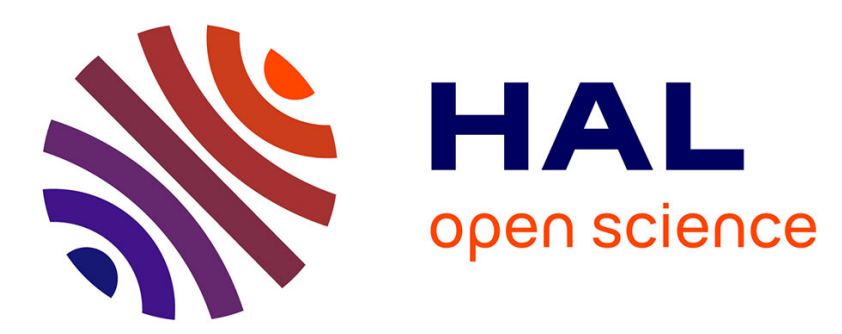

\title{
Modeling of plastic anisotropy with reduced polycrystalline models. Application to aluminum alloys
}

Gilles Rousselier, F. Barlat

\section{To cite this version:}

Gilles Rousselier, F. Barlat. Modeling of plastic anisotropy with reduced polycrystalline models. Application to aluminum alloys. 11th ESAFORM Conference on Material Forming, Apr 2008, Lyon, France. pp.269-272, 10.1007/s12289-008-0352-1 . hal-00391666

\section{HAL Id: hal-00391666 https://hal.science/hal-00391666}

Submitted on 19 Aug 2010

HAL is a multi-disciplinary open access archive for the deposit and dissemination of scientific research documents, whether they are published or not. The documents may come from teaching and research institutions in France or abroad, or from public or private research centers.
L'archive ouverte pluridisciplinaire HAL, est destinée au dépôt et à la diffusion de documents scientifiques de niveau recherche, publiés ou non, émanant des établissements d'enseignement et de recherche français ou étrangers, des laboratoires publics ou privés. 


\title{
Modeling of plastic anisotropy with reduced polycrystalline models. Application to aluminum alloys
}

\author{
G. Rousselier ${ }^{1}$, F. Barlat ${ }^{2}$ \\ ${ }^{1}$ Centre des Matériaux, UMR CNRS 7633, Ecole Nationale Supérieure des Mines de Paris, ParisTech, BP 87, \\ 91003 Evry cedex, France \\ ${ }^{2}$ Alcoa Technical Center, Materials Science Division, 100 Technical Drive, Alcoa Center, PA 15069-0001, \\ USA. (Now at Graduate Institute of Ferrous Technology, Pohang University of Science and Technology, San \\ 31 Hyoja-Dong, Nam-Gu, Pohang, Gyeongbuk 790-784, Korea)
}

\section{e-mail: Gilles.Rousselier@ensmp.fr}

ABSTRACT: The modeling of deviations from isotropic hardening still is a difficult task for macroscopic models, in particular for non-proportional loading paths. The alternative polycrystalline models suffer from large CPU time in FE analyses and do not always give simultaneously a good description of flow stresses and transverse strain rates. Due to a specific parameter calibration procedure, a "reduced" polycrystalline model with 8 orientations only is in excellent agreement with all experimental curves for a 2090-T3 aluminum sheet. FE calculations of a punch test with contact and friction give CPU times only $15 \%$ larger than with a macroscopic model.

Key words: Anisotropy, Polycrystalline model, Texture, Finite element analysis, Aluminum.

\section{INTRODUCTION}

Concerning plastic anisotropy, many successful efforts have been made in the last years to improve macroscopic models [1][2][3]. Nevertheless, the modeling of deviations from isotropic hardening still is a difficult task for these models, in particular for non-proportional loading paths.

The alternative polycrystalline models suffer from large CPU time in FE analyses. Moreover, for a given experimental anisotropic texture, it was also shown that classical polycrystalline models do not always give simultaneously a good description of flow stresses and transverse strain rates, see for example [4][5]. A choice has to be made between the yield locus and the Lankford coefficients. This drawback could be prohibitive for accurate finite element calculations of structures.

The objective of the present work is to comply with two contradictory requirements:

- small CPU times with polycrystalline models, thanks to a small number $(<10)$ of crystallographic orientations ("grains"),

- good agreement with experimental stress levels and strain rates simultaneously.

\section{MATERIAL}

The material is a strongly anisotropic 2090-T3 aluminum-lithium alloy $1.6 \mathrm{~mm}$ thick sheet sample.
The yield stress $\left(\sigma_{11}\right)_{y}$ and Lankford ratio $r=\dot{\varepsilon}_{22}^{p} / \dot{\mathcal{E}}_{33}^{p}=\dot{\mathcal{\varepsilon}}_{\text {width }}^{p} / \dot{\mathcal{\varepsilon}}_{\text {thickness }}^{p}$ have been determined with tensile tests conducted every $15^{\circ}$ from the rolling direction. The yield stress $\sigma_{b}=1.035 \sigma_{\theta=0^{\circ}}$ and Lankford ratio $r_{b}=\dot{\varepsilon}_{22}^{p} / \dot{\varepsilon}_{11}^{p}=0.67$ corresponding to a biaxial stress tensor $\sigma_{11}=\sigma_{22}$ in the rolling and transverse directions are also known [1].

The database has been reconstructed from the experimental hardening curve in the rolling direction:

$\bar{\sigma}=646\left(0.025+\varepsilon^{p}\right)^{0.227}$

and from the experimental stresses and $\mathrm{r}$ ratios. The $r$-values are supposed to be independent of the strain level. The plastic strain range considered in the database is $\varepsilon^{p}=0.001-0.06$, with 13 experimental points for each curve: $\sigma_{11}-\varepsilon_{11}$ and $\varepsilon_{22}-\varepsilon_{33}$ in simple tension, $\sigma_{11}-\varepsilon_{33}$ and $\varepsilon_{22}-\varepsilon_{11}$ in biaxial tension. So parameter identification of the polycrystalline model has been performed with low to moderate strains, and not only at initial yielding. The reconstructed stress-strain curves are very close to the real experimental curves, with the exception of the biaxial curve for $\varepsilon_{11}>0.03$. The real experimental biaxial curve has been used for parameter identification. It shows that the hypothesis of isotropic hardening following equation (1) can be 
invalidated even in proportional loading.

The database has been completed with a strongly non-proportional loading: shear $\sigma_{12}$ followed by traction $\sigma_{11}$ in the rolling direction, an example of "orthogonal" loading. The data do not correspond to a real experimental test. This test is introduced to investigate the ability to model large crosshardening after a loading path change. The crosshardening is supposed to be in the order of $50 \mathrm{MPa}$.

\section{POLYCRYSTALLINE MODEL}

The following equations, where $\underline{m}_{s}, s=1$ to 12 , are the orientation tensors of the 12 slip systems of fcc crystallographic structures, and where $\underline{\sigma}_{g}$ is the stress tensor in the "grain" number $g$ (from 1 to $N$ ), are used:

$$
\begin{aligned}
& \tau_{s}=\underline{\sigma}_{g}: \underline{m}_{s}, \underline{\dot{\varepsilon}}^{p}=\sum_{s=1}^{12} \underline{m}_{s} \dot{\gamma}_{s} \\
& \dot{\gamma}_{s}=\dot{v}_{s} \operatorname{Sign}\left(\tau_{s}\right) \\
& \left.\dot{v}_{s}=\operatorname{Max} \mid 0,\left\{\left(\left|\tau_{s}\right|-r_{s}\right) / K\right\}^{n}\right\rfloor
\end{aligned}
$$

The hardening of the slip systems is supposed to be purely isotropic (no kinematic hardening):

$r_{s}=R_{0}+Q \sum_{t=1}^{12} H_{s t}\left[1-\exp \left(-b v_{t}\right)\right]$

The hardening matrix $H_{s t}$ depends on 6 parameters $h_{1}$ to $h_{6}$ [6]. The localization equations are [7]:

$$
\begin{aligned}
& \underline{\sigma}_{g}=\underline{\Sigma}+C\left(\underline{B}-\underline{\beta}_{g}\right), \underline{B}=\sum_{g=1}^{N} f_{g} \underline{\beta}_{g} \\
& \underline{\dot{\beta}}_{g}=\underline{\dot{\varepsilon}}_{g}^{p}-\underline{\underline{D}} \cdot \underline{\beta}_{g}\left(2 J_{2}\left(\underline{\dot{\varepsilon}}_{g}^{p}\right) / \sqrt{3}\right)
\end{aligned}
$$

Because of the non-linear evolution of the intermediate variables $\underline{\beta}_{g}$, these equations correctly capture the transition from elastic to plastic accommodation of the intergranular deformations. The scalar parameter $C$ is in the order of the shear modulus $\mu$, as in the self-consistent formalism. $\underline{\underline{D}}$ is a fourth-order tensor. With Voigt notations, the form of this tensor for orthotropic materials is:

$$
\underline{\underline{D}}=\left(\begin{array}{cccccc}
D_{11} & D_{12} & D_{13} & 0 & 0 & 0 \\
D_{21} & D_{22} & D_{23} & 0 & 0 & 0 \\
D_{31} & D_{32} & D_{33} & 0 & 0 & 0 \\
0 & 0 & 0 & D_{44} & 0 & 0 \\
0 & 0 & 0 & 0 & D_{55} & 0 \\
0 & 0 & 0 & 0 & 0 & D_{66}
\end{array}\right)
$$

As $\underline{\underline{D}}$ is a linear relation between two deviators, the coefficients obey 2 conditions (10 independent coefficients):

$$
D_{11}+D_{21}+D_{31}=D_{12}+D_{22}+D_{32}=D_{13}+D_{23}+D_{33}
$$

\section{RESULTS OF PARAMETER IDENTIFICATION}

The parameters of the polycrystalline model have been calibrated with Levenberg-Marquardt optimization algorithm and a specific identification procedure [8]. The 26 parameters of the polycrystalline model, including 6 Euler angles and 1 volume fraction for the texture, have been calibrated simultaneously on the 43 experimental curves of the database. Eq. (4) is viscoplastic: fixed parameters $n=25$ and $K=20 \mathrm{MPa}$ have been used for the rate-independent aluminum alloy, and the duration of all tensile tests is 1000 seconds. The hardening matrix is defined by $h_{1}=1, h_{2}=0.3177$, $h_{3}=0.0585, \quad h_{4}=0.2102, \quad h_{5}=1.6700$, $h_{6}=0.6925$. Other parameters are $R_{0}=82.6502$ MPa, $Q=31.4851 \quad \mathrm{MPa}, \quad b=17.3828 \quad$ and $C=46484 \mathrm{MPa}$. The resulting anisotropy of the localization equation (6) is:

$$
\underline{=}=\left(\begin{array}{cccccc}
1418.5938 & 34.5292 & 6.9363 & 0 & 0 & 0 \\
7.0579 & 1289.2333 & 10.9951 & 0 & 0 & 0 \\
2.0826 & 103.9718 & 1409.8029 & 0 & 0 & 0 \\
0 & 0 & 0 & 7.2973 & 0 & 0 \\
0 & 0 & 0 & 0 & 698.9113 & 0 \\
0 & 0 & 0 & 0 & 0 & 430.6919
\end{array}\right)
$$

Due to the large number of parameters and of experimental tests to be calculated at each step of the optimization process, the CPU times are prohibitive if a large number $N$ of crystallographic orientations are considered. That is why parameter identification can be completed only for reduced polycrystalline models, say with $N \leq 20$. Good results have been obtained with $N=8$ "grains". The resulting model is named RP8 in the following.

The model curves and experimental points are compared in Fig. 1 (ST: simple tension, BT: biaxial tension, S: shear). The RP8 model $\{111\}$ pole figure with 8 "grains" is shown in Fig. 2a. An orientation is defined by the 3 Euler angles $\left(\varphi_{1}, \Phi, \varphi_{2}\right)$ and its volume fraction $f$. Orthotropic symmetry gives the 3 associated orientations or "grains" $\left(-\varphi_{1}, \Phi,-\varphi_{2}\right)$, $\left(-\varphi_{1},-\Phi,-\varphi_{2}\right)$ and $\left(\varphi_{1},-\Phi, \varphi_{2}\right)$. In Fig. 2 a, 2 sets of 4 orientations close to the $\mathrm{S}$ and brass texture components are represented: (60.0839, 24.4331, 52.1730), $f=0.1149,(39.1266,36.1651,1.6579)$, $f=0.1351$. The experimental pole figure is shown in Fig. 2b. The objective is not to have a precise modeling of the experimental texture. Nevertheless, the good agreement between the 2 figures enables a good modeling of texture evolution. 
In order to test the computational efficiency of the reduced polycrystalline model, the punch test of Fig. 3 has been calculated. The complete mesh $\left(360^{\circ}\right)$ is made of 2567 nodes and 2460 linear 8noded finite elements with 8 integration points. Since the material is orthotropic, the $1 / 4$ mesh of Fig. 3 would have been sufficient. However, since the objective of this work is to test CPU times for different constitutive models, the larger mesh is more suitable.

The punch test has been calculated between $\mathrm{t}=0$ and 1000 seconds, corresponding to a punch displacement of $13.33 \mathrm{~mm}$. The finite strain option has been activated, but the texture evolution is not taken into account, as the maximum local strain is $\varepsilon_{33}=-0.217$ (thickness direction). The punch test was also calculated with the Bron and Besson [3] macroscopic model, BB in the following, calibrated with the simple and biaxial tensile tests. The loaddisplacement curves of the RP8 and BB models are shown in Fig. 4. The two curves differ due to some discrepancy of the BB model with the experimental database.

The CPU times of the RP8 and BB models are compared in Table 1. Only a Runge-Kutta algorithm was implemented for the polycrystalline model. An implicit algorithm has also been used for the macroscopic BB model. The calculations have been performed with the same single processor of a biprocessor AMD Opteron 248 (64 bits, $2.2 \mathrm{GHz}$ ). Table 1 shows that the CPU time of the reduced polycrystalline model is quite reasonable, although somewhat longer in the local integration of the material model.

\section{CONCLUSIONS}

With the reduced polycrystalline model, two contradictory requirements have been fulfilled: (i) to preserve reasonable CPU times with physical slip systems, (ii) to improve the agreement with experimental stress levels and strain rates (Lankford coefficients) simultaneously. It enables the use of the model in industrial applications.

Table 1. CPU times with the polycrystalline RP8 model and the macroscopic BB model.

\begin{tabular}{|l|l|l|l|l|l|}
\hline model & $\begin{array}{l}\text { algor- } \\
\text { ithm }\end{array}$ & $\begin{array}{l}\text { load } \\
(\mathrm{N})\end{array}$ & $\begin{array}{l}\text { CPU } \\
\text { time } \\
(\mathrm{s})\end{array}$ & $\begin{array}{l}\text { local } \\
\text { integ. } \\
(\mathrm{s})\end{array}$ & $\begin{array}{l}\text { contact } \\
\text { flexibility } \\
\text { matrix (s) }\end{array}$ \\
\hline RP8 & RK & 36974 & 33473 & 4851 & 16968 \\
\hline BB & RK & 41987 & 29981 & 1500 & 16998 \\
\hline BB & impl. & 41978 & 31505 & 2844 & 17067 \\
\hline
\end{tabular}

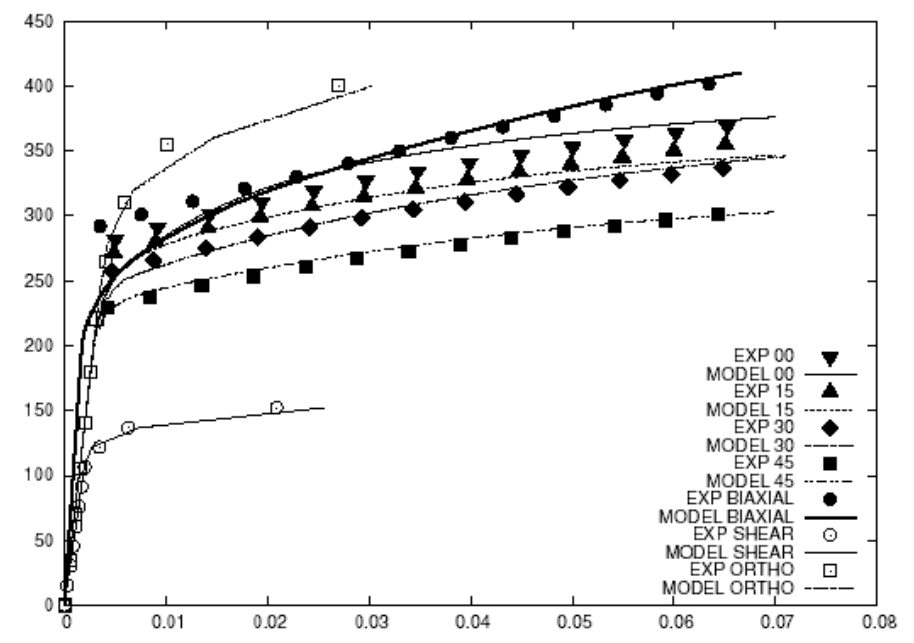

Fig. 1a. Stress-strain curves. ST $0^{\circ}, 15^{\circ}, 30^{\circ}, 45^{\circ}$, BT, S, orthogonal.

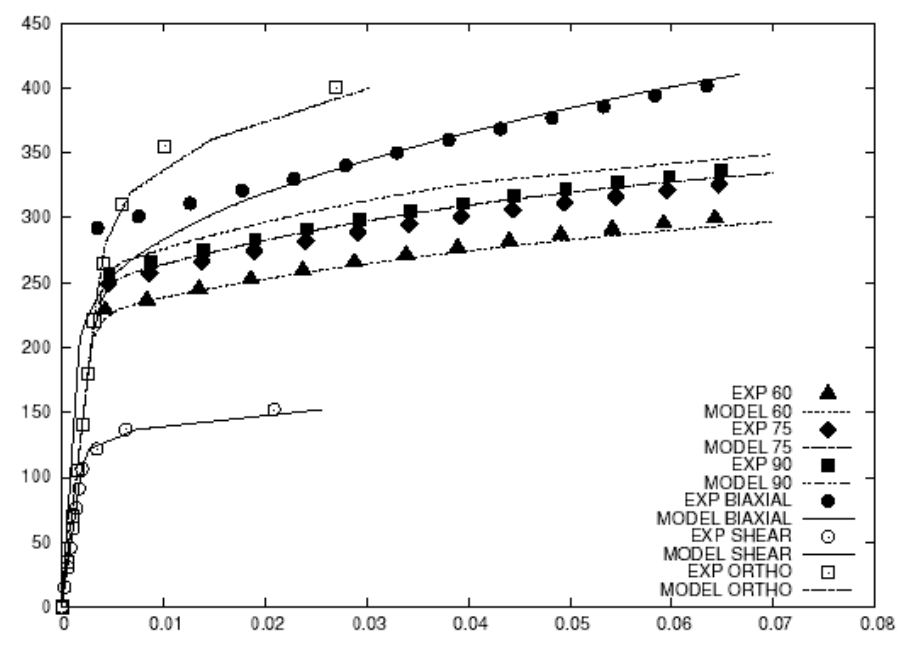

Fig. 1b. Stress-strain curves. ST $60^{\circ}, 75^{\circ}, 90^{\circ}$, BT, $\mathrm{S}$, orthogonal.

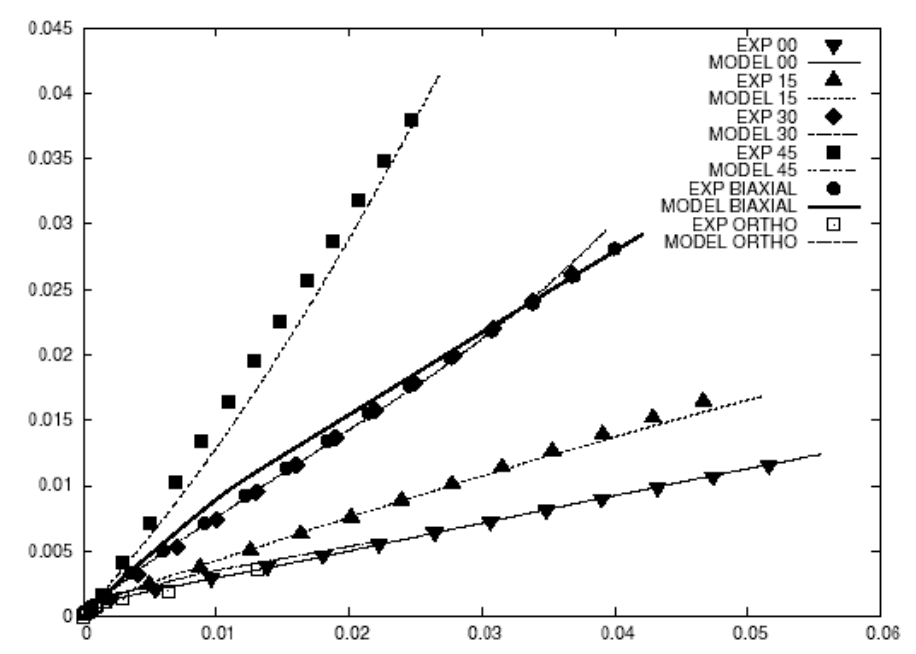

Fig. 1c. Transverse strains curves. ST $0^{\circ}, 15^{\circ}, 30^{\circ}$, $45^{\circ}, \mathrm{BT}$, orthogonal. 


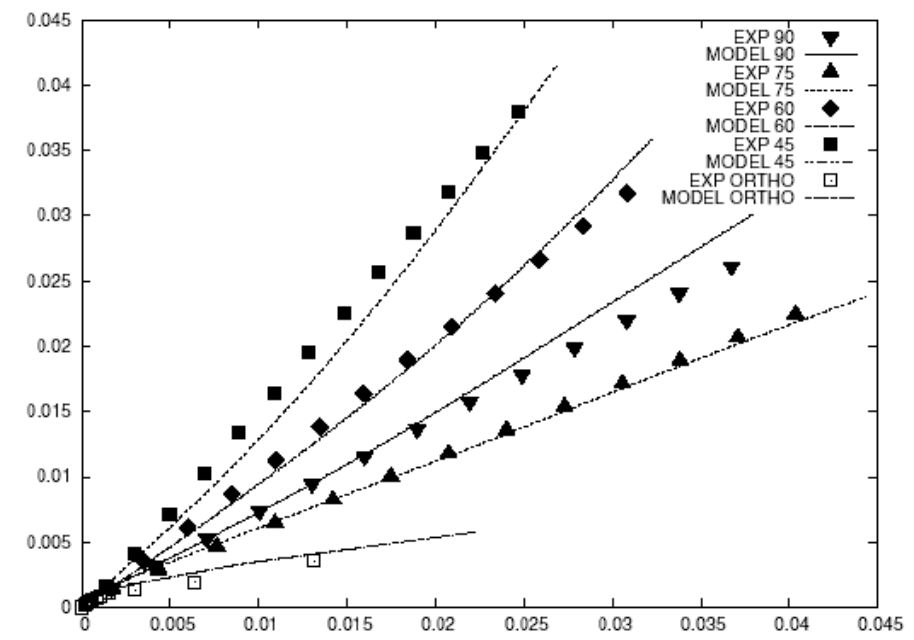

Fig. 1d. Transverse strains curves. ST $90^{\circ}, 75^{\circ}, 60^{\circ}$, $45^{\circ}$, orthogonal.
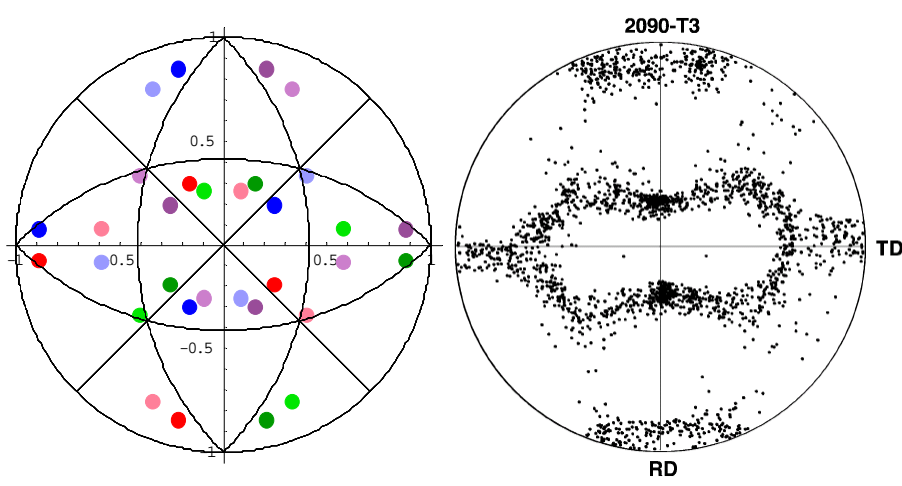

Fig. 2. $\{111\}$ pole figures of aluminum alloy 2090T3, RP8 model (2a, left), experimental (2b, right) [2].

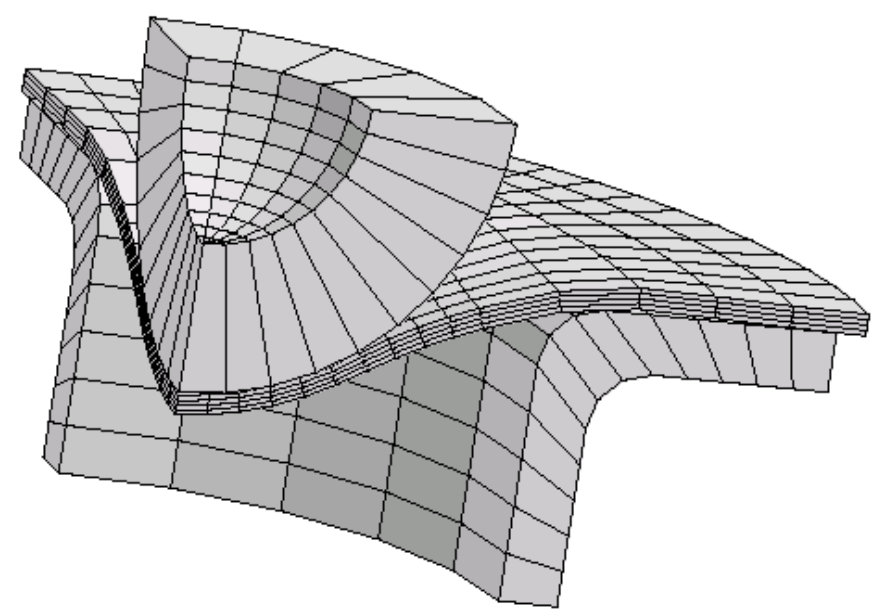

Fig. 3. Finite element model of the punch test: $1 / 4$ of the complete $360^{\circ}$ mesh used in calculations. The $1.6 \mathrm{~mm}$ thick sheet is fixed on a die with a $64 \mathrm{~mm}$ circular hole. The punch diameter is $53.33 \mathrm{~mm}$. The sheet has 4 finite elements in its thickness. Punch displacement: $13.33 \mathrm{~mm}$.

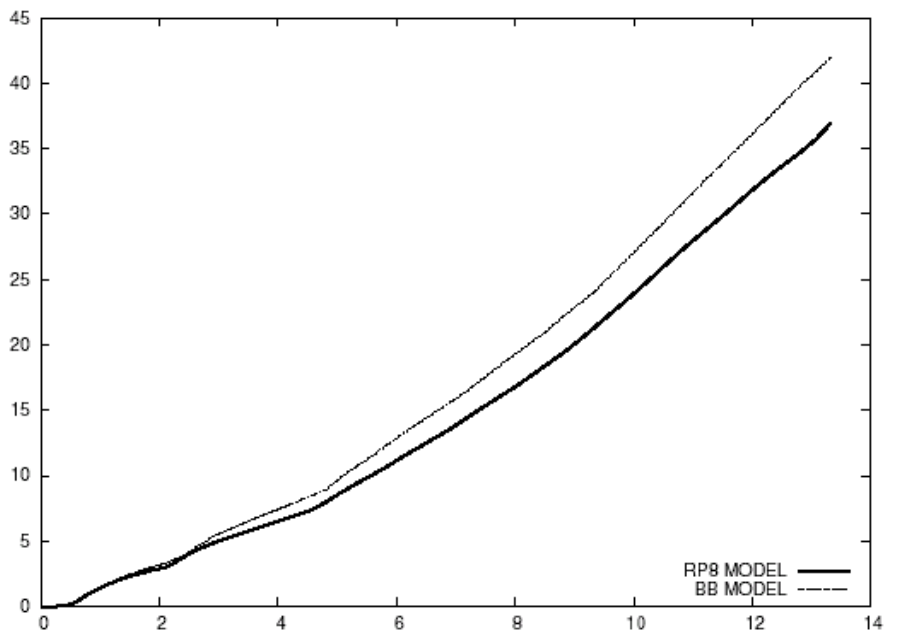

Fig. 4. Calculated load (kN)-displacement (mm) curves of the punch of Fig. 3. RP8: polycrystalline model with 8 "grains", BB: macroscopic BronBesson model.

\section{ACKNOWLEDGEMENTS}

The authors are grateful to Profs G. Cailletaud and J. Besson for their help in the use of Zmat and Zebulon softwares.

\section{REFERENCES}

1. Barlat, F., Brem, J.C., Yoon, J.W., Chung, K., Dick, R.E., Lege, D.J., Pourboghrat, F., Choi, S.-H., Chu, E., Plane stress yield function for aluminum alloy sheets - part 1: theory. Int. J. Plasticity 19, (2003), 1297-1319.

2. Barlat, F., Aretz, H., Yoon, J.W., Karabin, M.E., Brem, J.C., Dick, R.E., Linear transformation-based anisotropic yield functions. Int. J. Plasticity 21, (2005), 1009-1039.

3. Bron, F., Besson, J., A yield function for anisotropic materials - Application to aluminum alloys. Int. J. Plasticity 20, (2004), 937-963.

4. Darrieulat, M., Montheillet, F., A texture based continuum approach for predicting the plastic behaviour of rolled sheet. Int. J. Plasticity 19, (2003), 517-546.

5. Lopes, A.B., Barlat, F., Gracio, J.J., Ferreira Duarte, J.F., Rauch, E.F., Effect of texture and microstructure on strain hardening anisotropy for aluminum deformed in uniaxial tension and simple shear. Int. J. Plasticity 19, (2003), 122.

6. Méric, L., Poubanne, P., Cailletaud, G., Single crystal modeling for structural calculations - Part I: model presentation. J. Engng. Mater. Technol. 113, (1991), 162170.

7. Sai, K., Cailletaud, G., Forest, S., Micro-mechanical modeling of the inelastic behavior of directionally solidified materials. Mechanics of Materials 38, (2006), 203-217.

8. Rousselier, G., Procédé pour déterminer un modèle polycristallin destiné à représenter le comportement d'un matériau solide soumis à une sollicitation mécanique. Demande de brevet d'invention $\mathrm{n}^{\circ} 0703215$ du 4 mai 2007. 